\title{
El arte de Martha Cajías ${ }^{1}$
}

\author{
Michela Pentimalli \\ Crítica de arte y directora del Espacio Simón I. Patiño, La Paz
}

\begin{abstract}
The aim of this article is to provide an interpretation of key issues in Martha Cajías' work, such as the multifaceted dialectics of fertility and maternity, life and death, memory and dreams, ethics of the ancestors, collective myths and family myth, and among all this, the overwhelming presence of Andean epistemology.
\end{abstract}

Keywords

community, father-mother-children, life-death, woman-nature, Pachamama

\footnotetext{
${ }^{1}$ Texto extractado de la tesis de Maestría en Antropología Filosófica "Tiempos y espacios de la memoria. La problemática antropológica en las formaciones de cuatro artistas contemporáneas bolivianas a partir de la comprensión del arte y de la labor del intérprete propuesta por la hermenéutica de Hans-Georg Gadamer" (2001). Con variaciones mínimas, fue publicado en el catálogo Martha Cajías (2009). La versión que ahora se publica es una versión revisada que incluye todas las ilustraciones a las que se hace referencia.
} 


\section{Resumen}

El propósito de este trabajo es ofrecer una interpretación de aspectos cruciales en la obra de Martha Cajías, como por ejemplo la compleja dialéctica fertilidad-maternidad, vida-muerte, memoria y sueños, la ética de los ancestros, los mitos colectivos, el mito familiar, y en medio de todo, la enorme presencia de la epistemología andina.

\section{Palabras claves}

comunidad, mujer-naturaleza, Pachamama, padre-madre-hijos, vida-muerte

En las obras de Martha Cajías, el mito juega un papel fundamental. Sus formaciones artísticas "son" mitos que ella misma construye, apropiándose de elementos de la memoria colectiva, cultural, social y familiar (mesocosmos), ${ }^{2}$ y de la memoria personal (microcosmos). De esta manera, actualiza las funciones universales del mito y trasciende hasta lo universal (macrocosmos). ${ }^{3}$

Una mirada general al conjunto de sus obras descubre inmediatamente la presencia obsesiva de la fertilidad y de la maternidad, siempre acompañada por la imposibilidad de alumbrar y por la muerte. En Pacarina

\footnotetext{
${ }^{2}$ Utilizo aquí la terminología de Joseph Campbell porque me parece adecuada para expresar las complejas dimensiones que se imbrican en la "mitología creativa". Ésta surge de "las intuiciones, los sentimientos, el pensamiento y la visión de un individuo idóneo, fiel a los valores de su experiencia" (Campbell 27).

${ }^{3}$ En el terreno del mito, Campbell identifica cuatro funciones: "La primera función de una mitología es reconciliar a la conciencia que despierta con el mysterium tremendum et fascinans de este universo tal como es; la segunda, presentar una imagen interpretativa total del mismo, tal como lo conoce la conciencia contemporánea (24-25). La tercera función consiste en la imposición de un orden moral: "...la adaptación del 'individuo a las exigencias de su grupo social, histórica y geográficamente condicionado" (25). Finalmente, la cuarta función, "...la más crítica y vital de una mitología es, por tanto, ayudar al individuo a centrarse y desenvolverse íntegramente, de acuerdo con a) él mismo (el microcosmos), b) su cultura (el mesocosmos), c) el universo (el macrocosmos) y d) el terrible misterio último que está dentro y más allá de todas las cosas:

De donde retroceden las palabras, Junto con la mente, sin haber llegado Taittiriya Upanisad'. (27)

La última parte del fragmento recuerda "lo real" de Lacan (véase la voz réel, en Chemama 237).
} 
(fig. 1), ${ }^{4}$ por ejemplo, dibuja un mítico útero cósmico en el que encierra animales alusivos como el sapo y la víbora.

Todos ellos son símbolos acuáticos de la lluvia, de lo mojado, de lo húmedo y son atributos que acompañan lo femenino. Al centro de este espacio hay una figura humana, sin manos, los brazos troncos (u ocultos) y los ojos cerrados. Mirándola se piensa en un feto y al mismo tiempo en un muerto. Las piernas -piedras- obstruyen la salida. La imagen es ambigua: el útero puede ser también un cerebro y los animales, las pesadillas de la memoria.

Un elemento recurrente en sus obras es el árbol. Para citar un título entre muchos, en Os sonhos são a unica consolação das mulheres (fig. 2), las raíces y las ramas abarcan todo el cosmos, convirtiéndose, simultáneamente, en metáfora del espacio y del tiempo. Las raíces son el espacio de abajo; las ramas, el espacio de arriba. Las raíces son el tiempo pasado, la historia que sostiene (soporta y alimenta) al individuo, a la familia y a la comunidad. Las ramas son el tiempo presente que se proyecta hacia el futuro y que sostiene (soporta y alimenta) los frutos. Se percibe una genealogía que se autoalimenta, como si hubiera un principio generador interno; el árbol mismo está "encinta" pero las energías están dirigidas hacia reforzar las raíces de ese mismo organismo evitando que las ramas retoñen. Hay cordones umbilicales y una rama sale del ombligo de la mujer. La sirena y el macho cabrío significan la sexualidad femenina y masculina.

La identificación entre la mujer y la naturaleza, en la función fecundante y reproductora, se reitera en Mujeres y lunas (fig. 3). Las fases de la luna marcan los ciclos de la fertilidad femenina y de la tierra. Las cuatro figuras de la composición están orientadas en dirección de los puntos cardinales y se ordenan alrededor de un centro-ombligo del universo, el lugar cero y el tiempo cero de la creación, acto cosmogónico que se repite en un eterno retorno. Exhiben su sexo, dispuestas al coito fecundante. Ellas representan también los cuatro elementos constitutivos del cosmos (agua, tierra, fuego, aire), unidos por una suerte de cordón umbilical, que significa el fluir continuo del ciclo vital.

El tema del ciclo vital y del "eterno retorno" está presente con fuerza en

\footnotetext{
4 "El lago, la fuente, cueva o montaña donde se originaron el Héroe Civilizador y la humanidad, reciben el nombre de paqarina (lugar de nacimiento u origen)" (Montes 90).
} 
una obra anterior, Los muertos saben regresar (fig. 4), formación donde la artista juega con las analogías entre el vientre materno y la chullpa, entre el lugar de la gestación y el lugar de la sepultura. Entre la similitud de la posición del feto y la del cuerpo del difunto.

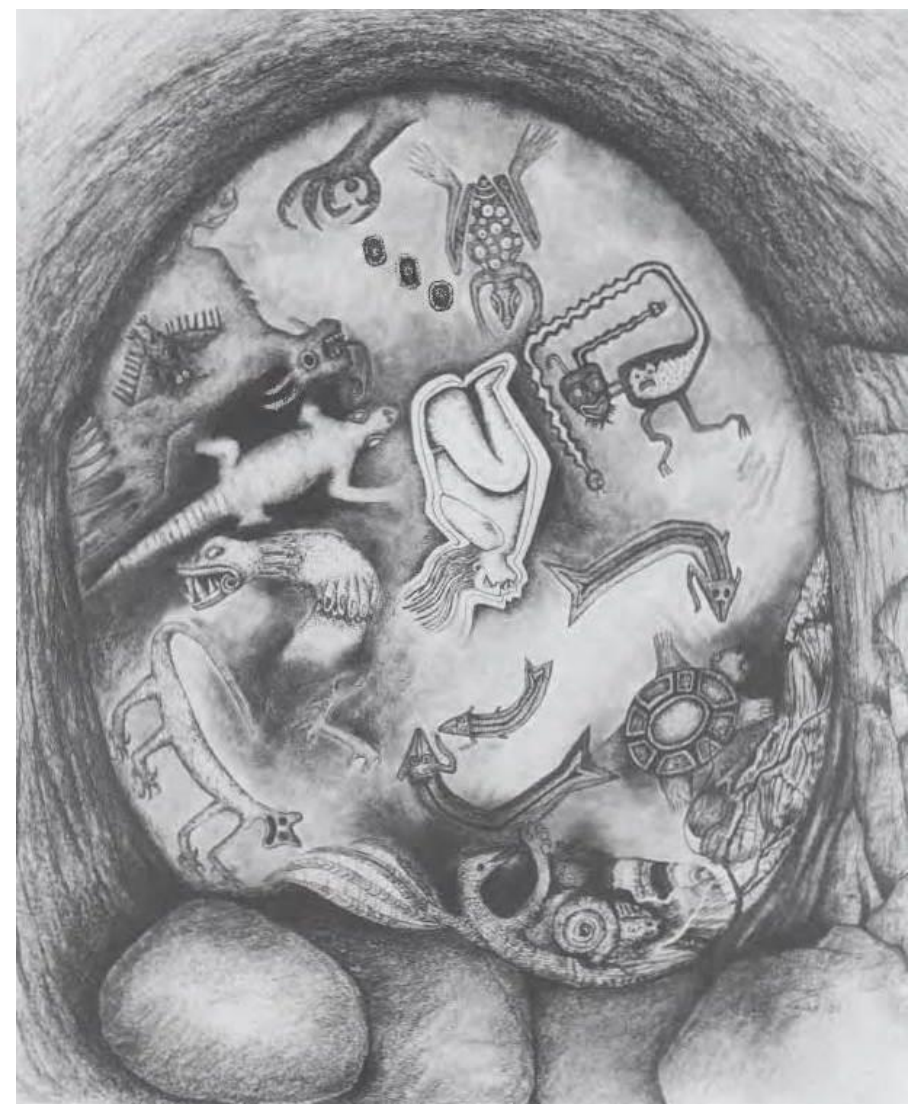

Figura 1. Pacarina (1994)

Dibujo a lápiz y carbón, 57 x 49 cm.

Colección particular, La Paz 


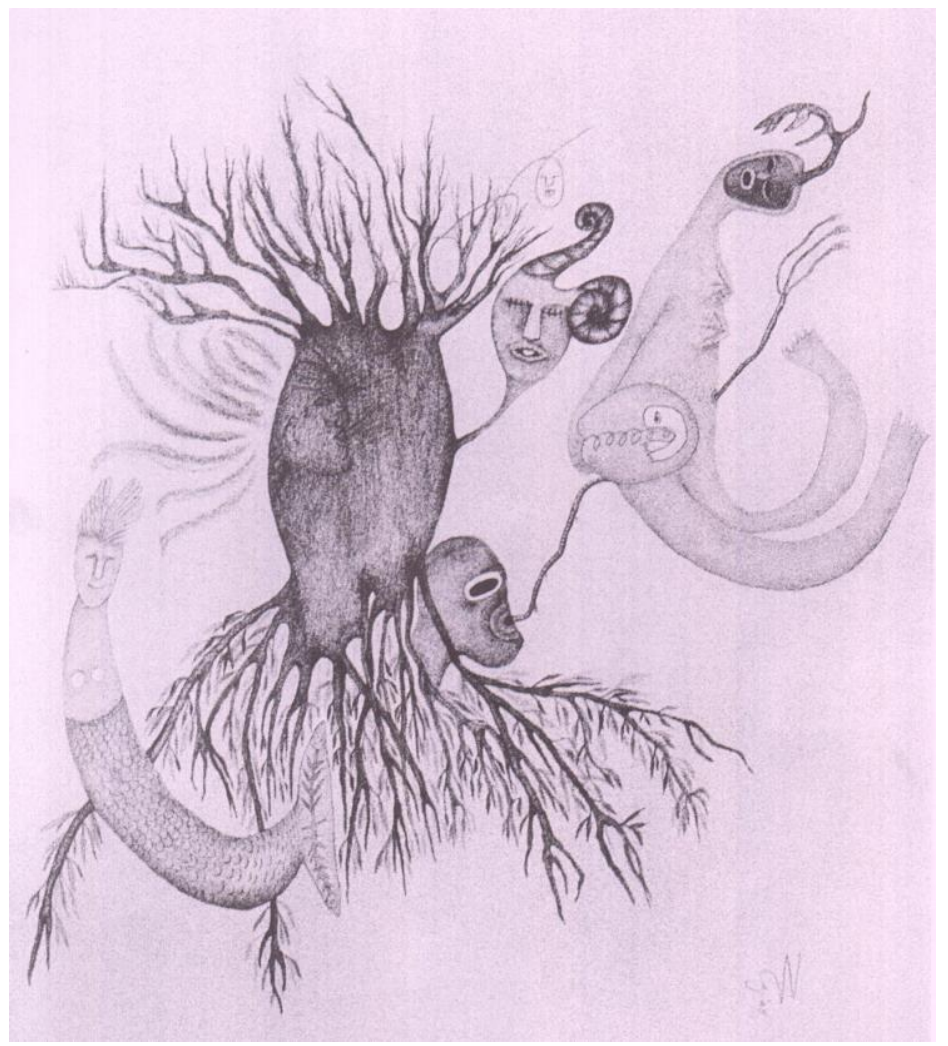

Figura 2. Os sonhos são a unica consolação das mulheres 1 (1997) Dibujo a lápiz y carbón, $57 \times 120 \mathrm{~cm}$. (parte de una trilogía) Colección particular, La Paz 


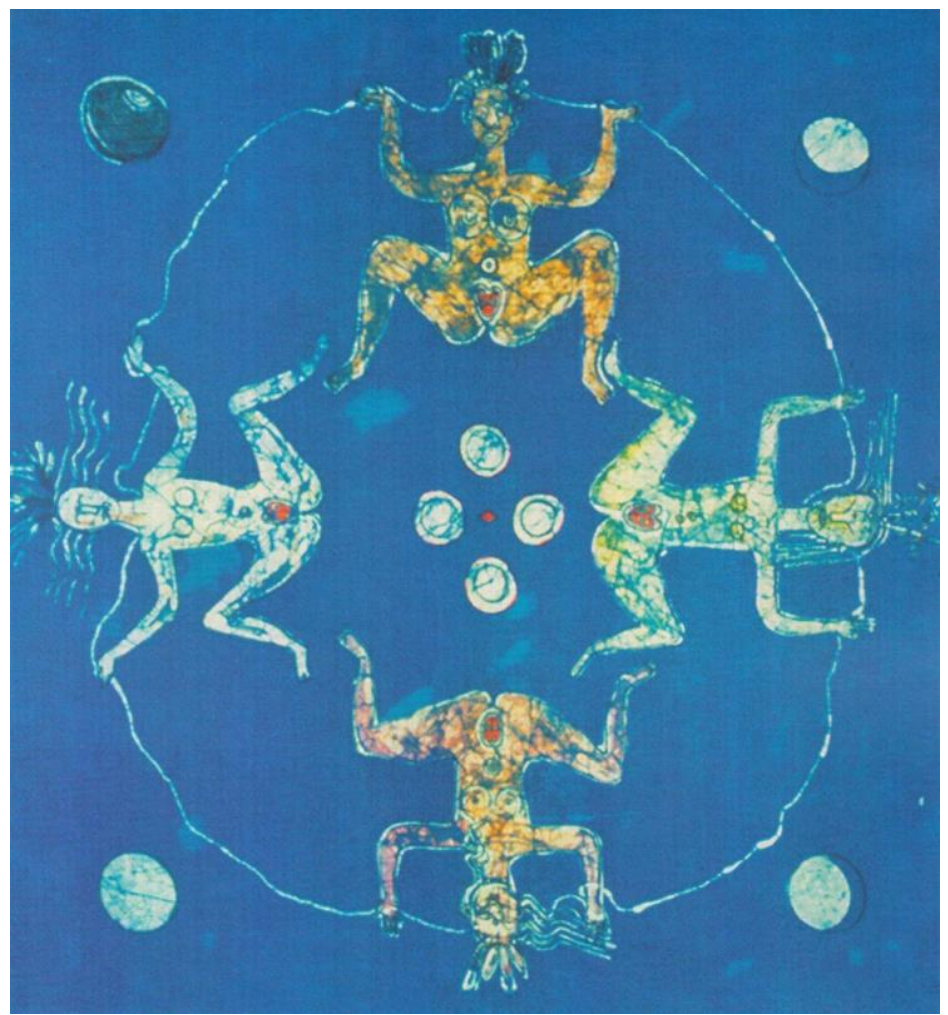

Figura 3. Mujeres y lunas (1987)

Batik sobre tela

Colección Loayza-Grisi, La Paz 


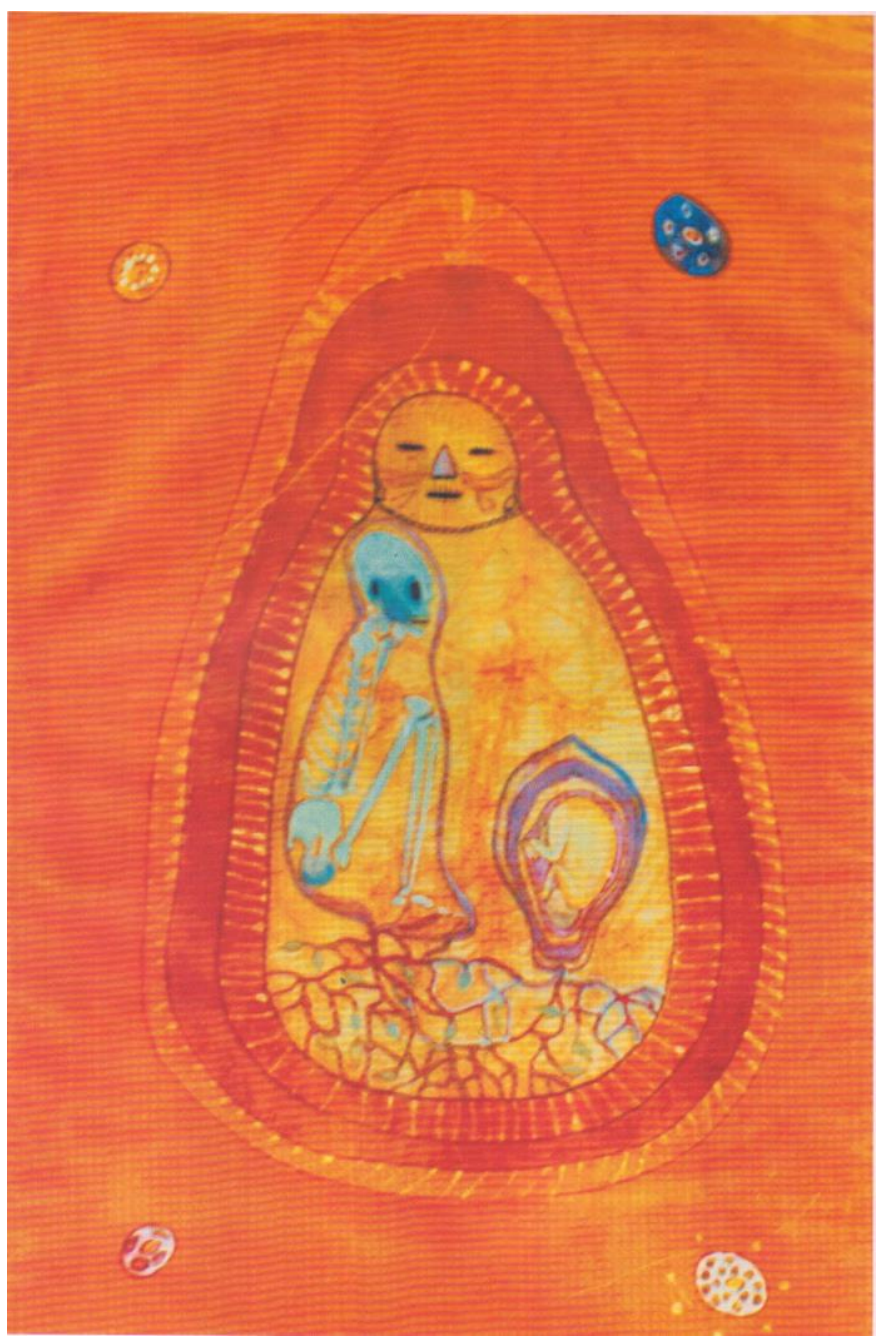

Figura 4. Los muertos saben regresar (1987)

Batik sobre tela

Colección particular, La Paz 


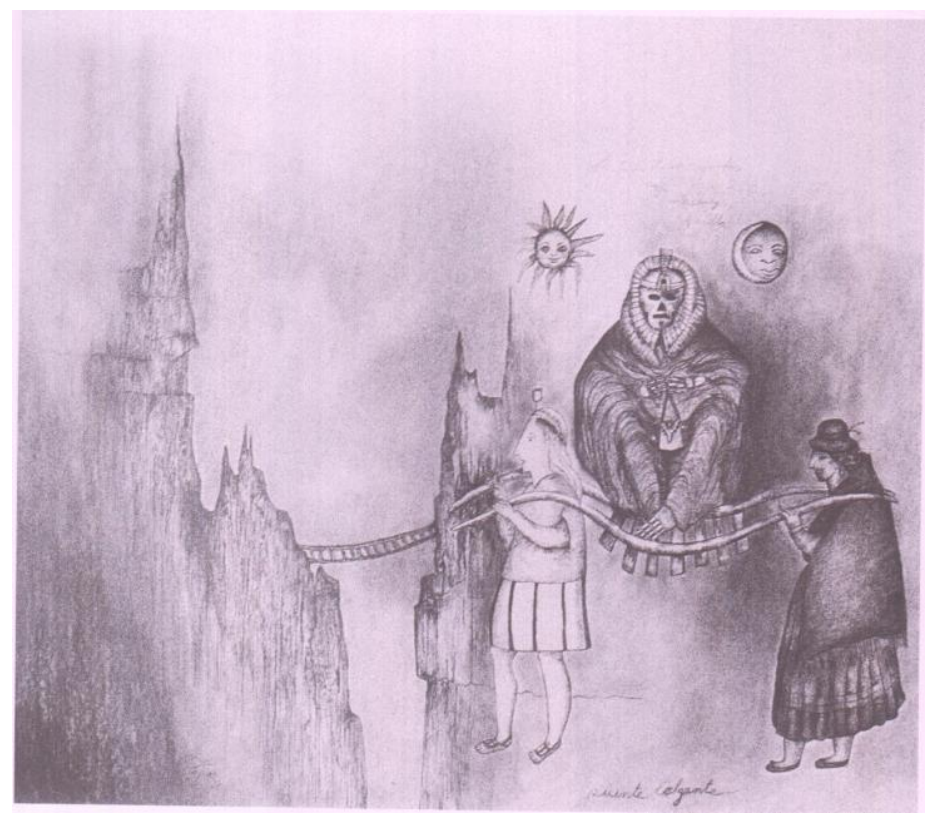

Figura 5. Puente colgante (1998)

Dibujo a lápiz y carbón, 53 x 54 cm.

Colección particular, La Paz 


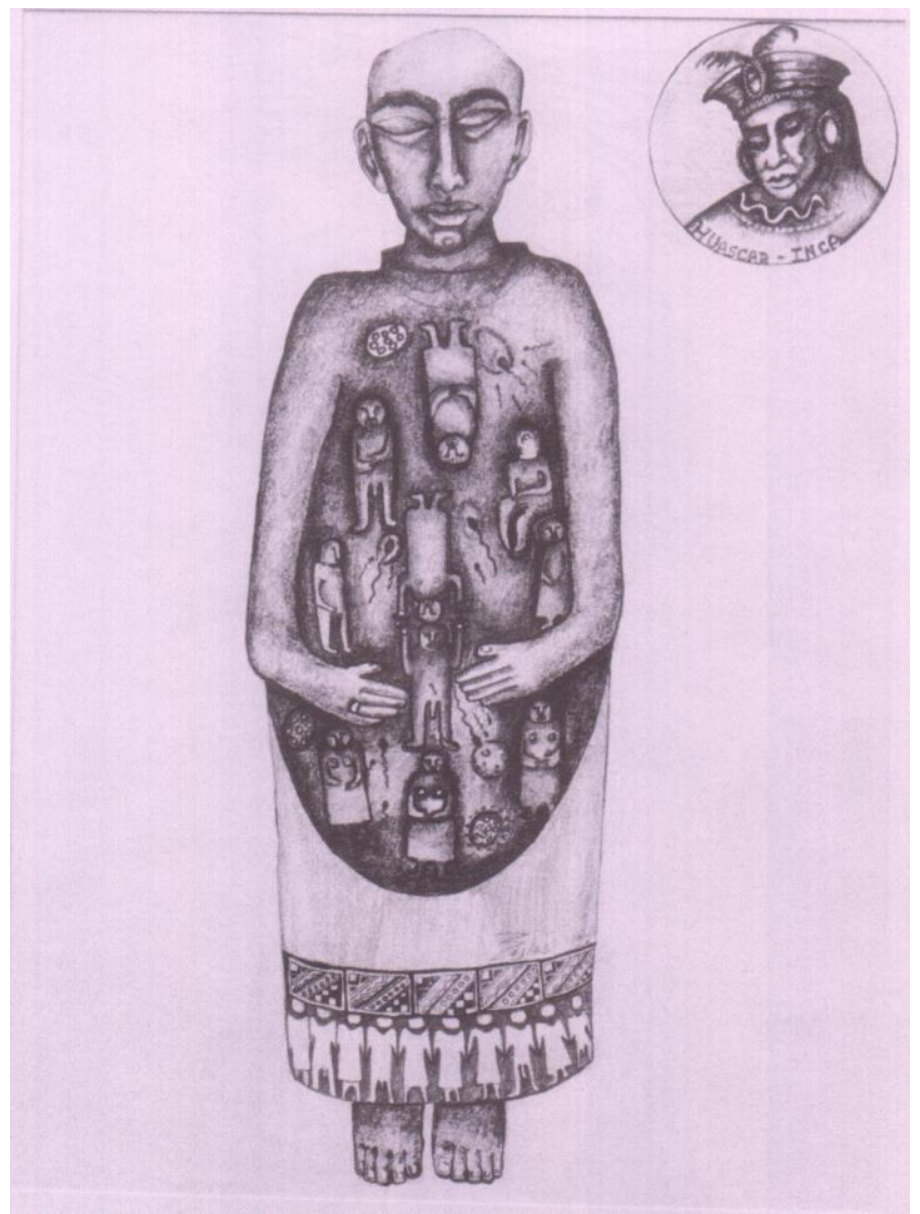

Figura 6. Homenaje a mi padre (1994)

Dibujo a lápiz, 58 x $50 \mathrm{~cm}$.

Colección particular, La Paz 


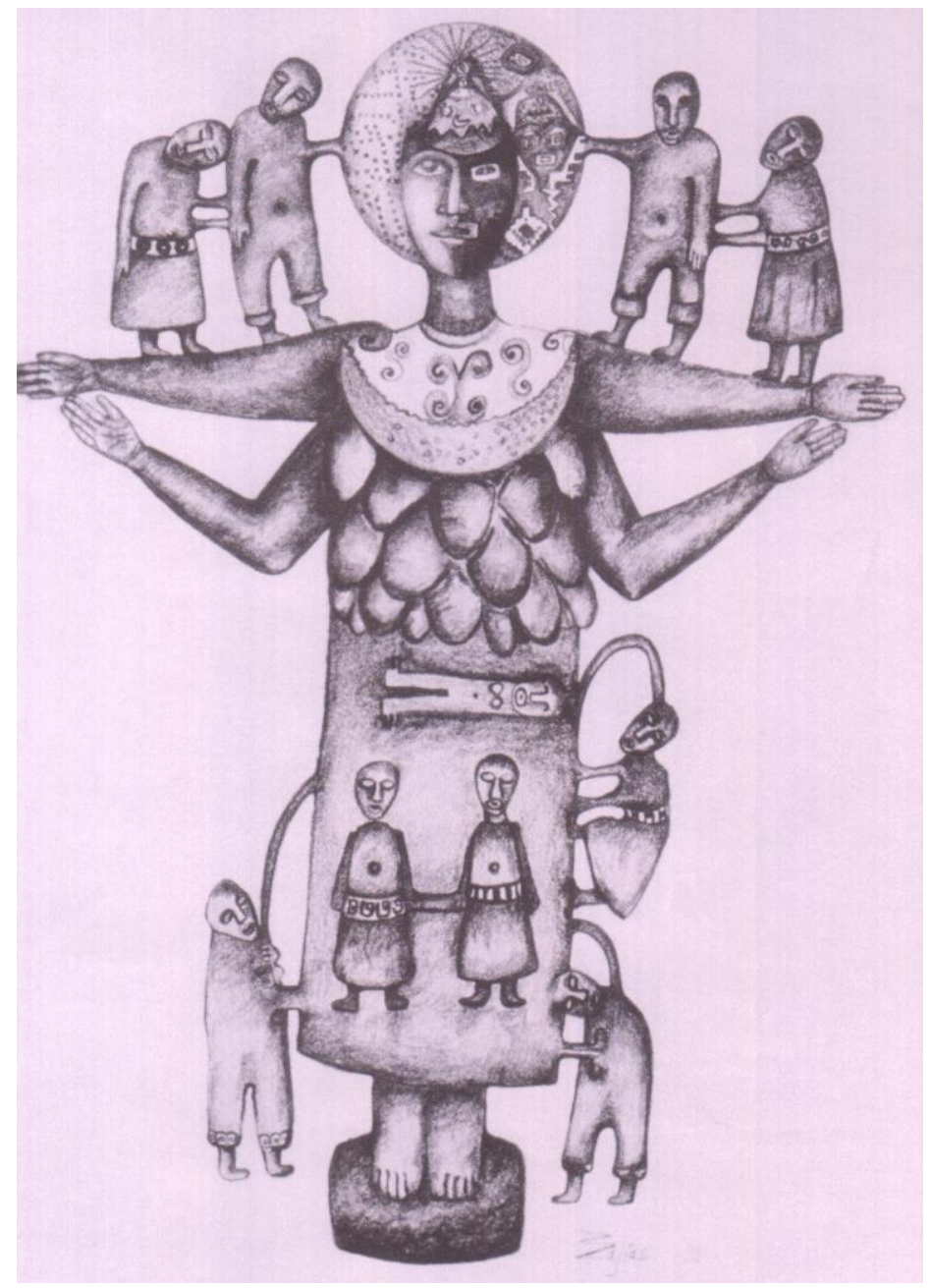

Figura 7. Homenaje a mi madre (1994)

Dibujo a lápiz, 58 x $50 \mathrm{~cm}$.

Colección particular, La Paz 
Metáforas de la pervivencia de los padres en nosotros y de la transmisión de esta herencia a los hijos ${ }^{5}$. Metáforas que trascienden a los individuos y a las familias y se amplían a los pueblos y a las culturas. Del cuerpo de la mujer al cuerpo social.

Martha Cajías trabaja también a partir de sus sueños, que reinventa en sus obras, como en Puente colgante (fig. 5). ${ }^{6}$ El sol y la luna asisten inconmovibles a lo que sucede en el mundo. El Inca y la chola paceña, hombre y mujer, no tienen un suelo donde apoyarse. De un lado y del otro del precipicio se elevan picos montañosos punzantes, agresivos, hostiles. El puente colgante entre dos extremos es metáfora de la vida. Los dos personajes lo deberán atravesar transportando un "ídolo" (una chullpa) con cabeza de calavera y manos de esqueleto, símbolo de la muerte, del destino.

Puedo "leer" la escena también como metáfora de la historia nacional. El Inca representa el pasado indígena prehispánico, la mítica Edad de Oro, con cuyo retorno sueña la tradición andina, mientras que la chola encarna el mestizaje que se ha producido desde la colonia. Los dos personajes cargan -hacia ninguna parte- el peso de la historia, simbolizada por la litera donde está acomodada la chullpa, que se parece a los rieles del ferrocarril, emblema de la modernidad soñada por las élites republicanas.

Enfocaré ahora mi atención en Homenaje a mi padre y Homenaje a mi madre (figs. 6 y 7), dos formaciones artísticas realizadas con economía de elementos, sobrias en términos estéticos, que remiten intencionalmente a iconografías ancestrales, pero ricas en potencialidades de interpretación. En los dos dibujos, la artista representa a sus progenitores como figuras hieráticas, sagradas, míticas, seleccionando, de la memoria colectiva, familiar y personal, aquellos elementos que le permiten realizar una construcción simbólica.

Homenaje a mi padre muestra, sobre un fondo vacío, una figura central masculina vestida con un uncu, la túnica incaica, adornada con una franja de diseños geométricos que recuerdan los tejidos andinos, y otra inmediatamente debajo, con diez figuras antropomorfas, masculinas $y$ femeninas, agarradas de la mano, como las de papel recortado. En la esquina

\footnotetext{
${ }^{5}$ Como podemos observar, Martha Cajías ha venido trabajando alrededor de algunos tópicos que emergen con insistencia, una y otra vez, en sus formaciones artísticas.

${ }^{6}$ Los sueños constituyen, para los pueblos andinos y otras culturas ancestrales, caminos de conocimiento que permiten "...leer, predecir o [...] revelar los acontecimientos" (Rocha 87).
} 
superior derecha, se encuentra una suerte de medallón donde está el rostro de "Huáscar Inca", ${ }^{7}$ como indica la inscripción. En la cabeza lleva la corona real. ${ }^{8}$ Esta imagen coincide con la iconografía de las series de los reyes Incas de la pintura popular tradicional colonial y republicana (Gisbert 115-147).

Los brazos y las manos de la figura central reposan sobre el vientre, que contiene en su interior diez figuras humanas, masculinas y femeninas, y espermatozoides, algunos de los cuales se encuentran fecundando óvulos. ${ }^{9}$ Además, se observa una especie de círculos que, a su vez, contienen círculos más pequeños, dibujos que llaman a la mente el proceso de la mitosis en las células fecundadas y también dan la idea de semillas. Las figuritas se distinguen sexualmente porque las femeninas llevan vestido y en algunos casos muestran los pechos, mientras que las masculinas se diferencian por mostrar el pene. Curiosa "discriminación", puesto que está el rasgo distintivo de la vestimenta.

Este "Gran Padre" es una figura ambigua; no existe una frontera definida entre el interior de su cuerpo y el exterior, así que podemos ver lo que contiene su vientre como una "continuación" de su túnica. Asimismo, hay una ambigüedad entre engendrado y engullido. Los hijos están adentro y no sabemos si "albergados" o "tragados". Dudamos entre la imagen de un Cronos que se los ha devorado para no "ceder el trono" a ninguno de ellos o de un padre "materno". Además, los ojos cerrados y las manos apoyadas sobre el vientre nos ubican en el límite entre la vida y la muerte.

Nuevamente nos encontramos frente a una actitud dual: "de mujer embarazada", que mira dentro de sí, en comunión con las criaturas que aloja en su vientre, o de padre celoso, que "guarda" a sus hijos más allá de la muerte, que los retiene y delimita con su ley -ley del padre, de la estirpe-, los encierra en ella, y los aísla de las amenazas externas de lo (los) de afuera. Aquí prevalece la pertenencia a un linaje. No hay posibilidad de salida, porque el alumbramiento significaría que los hijos se incluyeran en otras "fidelida-

\footnotetext{
${ }^{7}$ El padre de la artista se llamaba Huáscar.

${ }^{8}$ De acuerdo a Teresa Gisbert (122), la corona real estaba compuesta por tres elementos: Ilautu (vincha o guirnalda), mascaipacha (plancha o broche metálico que sujeta las plumas), unancha (borla que cuelga del pie de la lámina).

${ }^{9}$ La disposición de los espermatozoides que fecundan óvulos cerca de algunas de las figuras representadas ¿querrá señalar a los hijos que engendraron hijos?
} 
des", en otras "fratrías", resultando en una ruptura con la tradición, con la ley, con el grupo al que se pertenece y al que se quiere preservar.

Los elementos que remiten a la reproducción, colocados cerca de algunas de las figuritas, parecen indicar quiénes han cumplido con esa función. Estos procesos se gestan dentro del vientre paterno, es decir, entonces, que el padre ejerce el dominio sobre la reproducción. Este padre es Inca, ${ }^{10}$ rey de una estirpe, posee mando y sabiduría sobre los hombres y el cosmos. Es un señor todopoderoso, el enlace entre el cielo y la tierra, "...en cuyas manos está el destino de sus hijos" (Rocha 119). Es también principio generador vital, Héroe Fundador y Civilizador que, como hijo del dios sol, participa de lo humano y de lo divino:

El Inca es el mediador entre los hombres y los dioses, entre lo Bajo y lo Alto, entre el pasado y lo futuro: ente metafísico que equilibra los opuestos y sostiene el orden cósmico. [...] También es fuente del Kamay o fuerza vital que da la fertilidad, ampara y beneficia [...] "protegía a sus súbditos bajo su sombra, hacía hablar a las montañas y su soplo ponía al mundo en movimiento", dice una tragedia quechua (Montes 73).

Así, la única salida, si es que hubiera alguna, sería por expulsión, no por alumbramiento, porque este último significaría ingresar los hijos al mundo, reconociéndoles independencia. La salida por expulsión, a su vez, implicaría la consumación de un acto caníbal por parte de un padre que tragaría a sus hijos y que, eventualmente, los expulsaría sólo en calidad de "desecho", de elemento anómalo. Todo esto se da porque no hay salida de la reproducción de la estirpe. Esta percepción se refuerza si seguimos pensando en este padre como Inca, a quien ni siquiera la muerte logra vencer del todo:

Desde su derrota a manos del conquistador, el Inca ha abandonado su posición en lo Alto para desplazarse al subsuelo, donde espera aletargado el momento de regresar (Montes 241).

Seguirá presente de manera latente, en la estirpe, en los hijos, y volverá en cualquier momento, como un fantasma, reprimido pero no anulado (consultar las voces fantasme, refoulé, retour du refoulé, en Chemama 78, 240, 249).

El protagonista de Homenaje a mi madre (fig. 7) es un gran ídolo, una suerte de estatua (apoyada sobre una base) inmóvil y sagrada. La artista

\footnotetext{
${ }^{10}$ Sobre la figura del Inca en la simbología andina, ver Montes 24 y 73-74.
} 
utiliza elementos de distintas culturas ancestrales y de la religión cristiana, para componer una híbrida y hierática Maternidad triunfante, detrás de la cual se vislumbra la sombra aterradora de una Diosa-Madre, exigente y todopoderosa. Su cabeza está rodeada por una aureola, símbolo de santidad, y en su frente reconocemos a la Virgen. La aureola puede también ser un sol, que se corresponde con la luna que adivinamos en el pectoral. El rostro está dividido verticalmente en dos partes, una clara y una oscura; el ojo del lado izquierdo está abierto, mientras que el ojo del lado derecho está cerrado. Los cuatro brazos nos remiten a las diosas orientales, como la Kali del Olimpo hindú, bondadosa y cruel al mismo tiempo; los múltiples senos, a la Diana Efesia de los romanos (Artemisa de Éfeso, para los griegos). ${ }^{11}$ Esta diosa, en su advocación efesia, no es simplemente la convencional diosa de la caza de la mitología griega, es un ser que presenta también atributos múltiples y antagónicos entre ellos:

[...] La Gran Diosa fue siempre una divinidad con tres aspectos, virgen, madre y vieja sabia. Ella contenía dentro de sí todas las posibilidades femeninas y aquellos que la veneraban en el mundo antiguo estaban absolutamente conscientes de esto, así como del hecho de que la nodriza podía convertirse en un instante en una destructora (Chicago y LucieSmith 23).

Con esta formación artística, Martha Cajías se instala en el espacio femenino de la maternidad y de la fertilidad. La figura se presenta inmediatamente como símbolo de la función biológica reproductora y nutricia de la mujer; tiene un seno para cada hijo, como los mamíferos hembras. Visualiza también el vínculo entre la madre y los hijos, que no se corta con el destete sino que, inagotable, alimenta nuestras vidas de muchas maneras (por eso los "vínculos" son diversos y los hijos se unen al cuerpo de la madre en los más variados puntos). Tres de ellos están inclusive dentro del cuerpo que, como ya notamos en la imagen del padre, se confunde con la túnica, en

${ }^{11}$ Para Judy Chicago, esta diosa representa el poder femenino “....en cuanto dadora de vida, protectora y nodriza" (Chicago y Lucie-Smith 22). La imagen de Diana ha sido retomada por numerosas artistas del siglo XX, a partir de los años setenta. Recordaré, entre ellas, la performance de Louise Bourgeois, A Banquet, y a la misma Judy Chicago, con el plato de "Ishtal" en su instalación Dinner Party (1974-1979). La Diana Efesia interesó también a Freud, quien le dedicó un pequeño pero sugerente estudio ("Grande es Diana Efesia"), y a otros estudiosos, como al etnopsicoanalista Tobie Nathan (74-77). 
una ambigüedad entre lo interior y lo exterior. Algunas de las figuritas que representan a los hijos están unidas entre ellas. Me parece importante este elemento, porque remite a la idea de fratría. Los hijos dan la impresión de ser ciegos. ¿Qué es lo que no ven o no quieren ver estos edipos? No está clara además su adscripción sexual. Hay confusión entre vestimentas y atributos.

La Madre, erguida como una Madonna de la Alta Edad Media, extiende sus brazos para entregarse $y$, al mismo tiempo, para recibirnos. La representación, sin embargo, manifiesta también un carácter "terrible"; es una madre que no quiere cortar el "cordón" que ata a los hijos más allá del alumbramiento y más allá de la muerte. Cordones-cadenas-caminos que señalan y definen un "destino", imposibilitando el andar libre por el mundo, cargando el peso de la dependencia y del pasado (nuevamente aparece la idea de estirpe, de linaje, de memoria familiar).

La imagen es la de una Pachamama. ${ }^{12}$ Diosa de la fertilidad, mujer que coloca la semilla. Madre tierra que extrae de su propio cuerpo el alimento que los hijos necesitan. Pachamama es quien hace brotar (nacer) a los hombres:

Pero además ella es mujer que se engrandece hablando, enviando diversos mensajes a sus hijos; ella es chaska (estrella) que brilla y que transforma la oscuridad en claridad [...] Pachamama concede todo (Rocha 89- 90).

La Pachamama tiene también otra cara, es dual. Tiene un lado oscuro y un lado radiante. Es nutricia pero exige, al mismo tiempo, alimentos. Es la Señora, la dueña de la vida que demanda ser retribuida:

Pachamama es [...] la más accesible y oscura de las divinidades andinas [...] en las culturas andinas la Pachamama se caracteriza también por su malicia, voracidad y peligro (Harris 58-59).

\footnotetext{
${ }^{12}$ Refiriéndose a Pachamama Olivia Harris anota que: "posee varios significados. A pesar de esta multiplicidad, la flexibilidad del símbolo deriva en buena parte de su imagen de la madre. Deseo señalar que lo materno es usado como significante universal, un símbolo que iguala distintos grupos sociales que en los hechos están atravesados por relaciones de jerarquía y desigualdad. Habría que preguntarse si la madre y lo materno significan realmente lo mismo en todas las culturas; se usan en el discurso como significante universal, pero éste es precisamente el medio por el cual pueden ocultarse las diferencias" (Harris 58).
} 
La Pachamama es a la vez la divinidad andina más familiar y la más opaca. Su culto es casi universal y abarca no solamente el sector rural sino también las capas populares urbanas, por su íntima identificación con los campos cultivados y la fertilidad del suelo [...]. En aymara el vocablo mama [las cursivas son mías] no significa tanto "madre" como "señora". En quechua es al revés. Pero tiene también otra acepción antigua: la de wak'a, o cosa sagrada (Bouysse-Cassagne, Harris 45).

Las relaciones entre la Pachamama y los hombres y las mujeres (sus hijos) deben ser fluidas. ${ }^{13} \mathrm{Y}$ esta fluidez, justamente, da la idea de relaciones ininterrumpidas, en ambas direcciones.

Si descomponemos el término "pachamama" (Rocha 91 y ss.), vemos que está conformado por un concepto articulador, aymara y quechua, entre espacio y tiempo, entre lugar e historia. La Pachamama es así. "Madre (y Señora) del Pacha", madre (y Señora) del tiempo. En ella, el tiempo y el espacio convergen. Es el aquí y ahora; es el presente donde a través del ritual se actualizan los mitos.

Ahora bien, en las dos figuras de esta suerte de "pareja divina" se evidencia una ambigüedad sexual que remite al dualismo de la cosmovisión andina. ${ }^{14}$ En esa lógica, el padre y la madre de Martha Cajías cumplen funciones cruzadas. El padre tiene a los hijos adentro, "como si" estuviese embarazado, ${ }^{15}$ mientras que la madre los controla también en el afuera. En ambos personajes resalta la presencia de principios opuestos: masculino/femenino; nosotros/ellos; sagrado/profano; bien/mal... Estas polaridades, paradójicamente complementarias, son consustanciales con la condición humana y se inscriben en la visión antropológica "expuesta" por la artista. Así, este antagonismo complementario se convierte en una clave de interpretación, "la 'cifra' a través de la cual el hombre devela tanto las

\footnotetext{
${ }^{13}$ A partir de entrevistas realizadas a pobladores andinos, Diego Irrazaval traza los rasgos personales de la Pachamama y su carácter: "es nuestra Madre [...] nos da vida para compartir el uno con el otro [...] siempre necesitamos hacer ofrendas en gratitud [...] es fuerte y exigente [...] es buena y celosa [...] según nuestro comportamiento ella bendice a todos los necesitados y a toda aquella persona que tiene fe en Ella; por no acordarse, por burlarse, por prometer y no cumplir su ch'alla, me traerá males a mi persona" (Irrazaval 72 y ss.).

14 "...todo es hombre o mujer" (Platt 24).

15 "...la maternidad se experimenta en el kaypacha donde ella está presente y actuante. [...] En el kaypacha los hombres experimentan la especificidad de la mujer y sus roles, que posibilitan hacerse una imagen de la Pachamama, que también es mujer" (Rocha 96).
} 
estructuras del universo cuanto el significado mismo de su existencia" (Eliade 192).

La artista construye iconográficamente al padre y a la madre, entramando los mitos colectivos y el mito familiar, ambos ligados a la memoria y al olvido; es decir, a esas funciones selectivas que enlazan los muertos a los vivos de un mismo grupo, sometidos ambos a un destino ${ }^{16}$ de sujeción a la ley "divina" que presupone la pertenencia al grupo.

Las dos formaciones artísticas visualizan entonces un mito familiar que, al hacerse carne e historia, legitima una realidad y también impone una ética. La ética de los ancestros, de la familia, de la estirpe nutricia a la que se tiene que retribuir, en una relación de pertenencia que condiciona la vida y vence la muerte.

\section{Bibliografía citada}

BOUYSSE-CASSAGNE, Thérèse y Olivia Harris. 1987 “Pacha: en torno al pensamiento aymara". Tres reflexiones sobre el pensamiento andino.

Thérèse Bouysse-Cassagne, Olivia Harris, Tristan Platt y Verónica Cereceda, eds. La Paz: Hisbol. 1-60.

CAJÍAS, MARTHA. 2009. La Paz: Plural.

CAMPBELL, Joseph. 1988 [1959] Las máscaras de Dios. Madrid: Alianza.

CHEMAMA, Roland, dir. 1993 Dictionnaire de la psychanalyse. París: Larousse.

CHICAGO, Judy. 1996a. Beyond the Flowers: the Autobiography of a Feminist Artist. New York: Penguin Books.

---. 1996b. The Dinner Party. New York: Penguin Books.

CHICAGO, Judy y Edward Lucie-Smith. 1999. Women Contested Territory and Art. New York: Watson-Guptill.

ELIADE, Mircea. 1972 [1969]. La nostalgia delle origini. Brescia: Morcelliana.

FREUD, Sigmund. 1981 [1911]. "Grande es Diana Efesia". Obras completas. Tomo II. Madrid: Biblioteca Nueva. 1933-1934.

${ }^{16}$ Hado, fatum, la "palabra de los dioses"; es decir, su voluntad, el destino irrevocable (consultar Palazzi 137). 
GISBERT, Teresa. 1994 [1980]. Iconografía y mitos indígenas en el arte. La Paz: Gisbert y Cía, Fundación BHN.

HARRIS, Olivia. 1988. "La Pachamama: significados de la madre en el discurso boliviano". Mujeres latinoamericanas / Diez ensayos y una historia colectiva. Lima: Flora Tristán, Centro de la Mujer Peruana. 57-79.

IRRAZAVAL, Diego. 1988. "Mutación en la identidad andina: Ritos y concepciones de la divinidad". Allpanchis 31 (1988): 20-90.

LACAN, Jacques. 1997 [1981]. El seminario. Libro 3. Las psicosis (1955-1956). Barcelona: Paidós.

LUCIE-SMITH, Edward. 1999 [1972]. Sexuality in Western Art. Singapore: Thames and Hudson.

MONTES, Fernando. 1984. Simbolismo y personalidad aymara en la historia. La Paz: Quipus.

NATHAN, Tobie. 1995 [1988]. Psychanalyse paiene. París: Ed. Odile Jacob.

PALAZZI, Fernando. s/f. Dizionario illustrato di mitologia. Milano: Mondadori, Edizione XXVI.

PENTIMALLI, Michela. 2001. "Tiempos y espacios de la memoria. La problemática antropológica en las formaciones de cuatro artistas contemporáneas bolivianas a partir de la comprensión del arte y de la labor del intérprete propuesta por la hermenéutica de Hans-Georg Gadamer". Tesis de Maestría en Antropología Filosófica. Facultad de Filosofía. Universidad Católica Boliviana San Pablo. Cochabamba, Bolivia.

---. 1988. "1968-1988: Veinte años después". Economía y sociedad (suplemento de Opinión). Cochabamba, 21 de mayo. 4-5.

ROCHA, José Antonio. 2000. Con el ojo de adelante y con el ojo de atrás: Ideología étnica, el poder y lo político entre los quechua de Cochabamba (1935-1952). La Paz: UCB, Plural, UMSS.

\section{$(C))$ BY-NG-ND}

ULLS
This work is licensed under a Creative Commons AttributionNoncommercial-No Derivative Works 3.0 United States License.

This journal is published by the University Library System of the University of Pittsburgh as part of its D-Scribe Digital Publishing Program, and is cosponsored by the University of Pittsburgh Press. 